\title{
Steering polymer growth by molding nanochannels: 1,5-hexadiene polymerization in high silica mordenite.
}

\author{
Marco Fabbiani $^{[\mathrm{a}],[\mathrm{b}]}$, Giorgia Confalonieri ${ }^{[\mathrm{c}]}$, Sara Morandi $\mathrm{i}^{[\mathrm{a}],[\mathrm{b}]}$, Rossella Arletti ${ }^{[\mathrm{c}] *}$, Simona Quartieri ${ }^{[\mathrm{c}]}$, \\ Mario Santoro $^{[\mathrm{d}]}$, Francesco Di Renzo ${ }^{[\mathrm{e}]}$, Julien Haines ${ }^{[\mathrm{e}]}$, Riccardo Fantini ${ }^{[\mathrm{c}]}$, Gloria Tabacchi ${ }^{\left[{ }^{[f]}\right.}$, Ettore \\ Fois $^{[\mathrm{f}]}$, Giovanna Vezzalini ${ }^{[\mathrm{c}]}$, and Gianmario Martra ${ }^{[\mathrm{a}],[\mathrm{b}]_{*}}$
}

[a] Dr. M. Fabbiani, Dr. S. Morandi, Prof. Dr. G. Martra

Dipartimento di Chimica

Università degli Studi di Torino

Via Pietro Giuria 7, 10125 Torino, Italy

E-mail: gianmario.martra@unito.it

[b] Dr. M. Fabbiani, Dr. S. Morandi, Prof. Dr. G. Martra

Interdepartmental Centre "Nanostructured Interfaces and Surfaces" - NIS

Università degli Studi di Torino

Via Pietro Giuria 7, 10125 Torino, Italy

[c] Dr. G. Confalonieri, Dr. R. Fantini, Prof. Dr. R. Arletti, Prof. Dr. S. Quartieri, Prof. Dr. G. Vezzalini,

Dipartimento di Scienze Chimiche e Geologiche

Università degli Studi di Modena e Reggio Emilia

Via Campi 103, 41125 Modena, Italy

E-mail: rossella.arletti@unimore.it

[d] Dr. M. Santoro

Istituto Nazionale di Ottica, CNR-INO, and European Laboratory for Non Linear Spectroscopy LENS

Via Nello Carrara 1, 50019 Sesto Fiorentino, Italy

[e] Dr. J. Haines, Dr. F. Di Renzo

ICGM, Univ. Montpellier, CNRS, ENSCM, Montpellier, France

Place Eugène Bataillon, 34095 Montpellier, France

[f] Prof. Dr. G. Tabacchi, Prof. Dr. E. Fois

Dipartimento di Scienza ed Alta Tecnologia and INSTM

Università degli Studi dell'Insubria

Via Valleggio 11, 22100 Como, Italy

E-mail: gloria.tabacchi@uninsubria.it

Supporting information for this article is given via a link at the end of the document.

\begin{abstract}
Zeolites are known as scaffolds for the assembly of molecules via non-covalent interactions, yielding organized supramolecular materials. Yet their potential in driving the growth of low-dimensional systems requiring covalent bond formation is still uncharted. We incorporated 1,5-hexadiene in the channels of a high-silica mordenite and analyzed the material by infrared spectroscopy, X-Ray powder diffraction, thermogravimetric and modeling techniques. Thanks to the few zeolite acid sites, 1,5-hexadiene experiences a slow conversion to a polymer, mainly formed by cyclopentane units and featuring short side chains able to fit the channels. The shape-directing abilities of zeolite framework play a two-fold role, involving first the organization of the monomers inside the void-space and then the linear growth of the chain, dictated by the channel geometry. These findings highlight the molding action of zeolites in directing transformations of covalent bonds under ambient conditions and may provide insights for obtaining confined polymers with intriguing perspective applications.
\end{abstract}

\section{Introduction}

The organization of objects, like molecules or clusters, in lowdimensionality nanosized structures is the key to attain materials endowed with new functionalities. ${ }^{[1-4]}$ This leitmotiv in advanced material science often relies on spontaneous assembly mechanisms - such as molecular recognition or intermolecular interactions - which could be enhanced or accelerated by imparting proper external stimuli e.g. via electromagnetic fields, ${ }^{[5]}$ chemical reagents, or by imposing geometric restrictions. ${ }^{[3,6-10]}$ In the latter instance, materials exhibiting empty nanospace arrays are especially attractive because their pores can be exploited as nanosized receptors for the matter to create confined, supramolecular structures with low-dimensionality. ${ }^{[1]}$ The preparation and exploitation of low-dimensionality materials is still a fundamental issue in nanoscience and nanotechnology. Microporous materials such as zeolites are of great interest in this context because of their unique pore topologies. ${ }^{[12]}$ The "open space" of zeolites can be filled by suitable encapsulated guest molecules and cations, that can diffuse in the pores and organize in low-dimensional aggregates tailored by zeolite channels. ${ }^{[1-15]}$ Moreover, the fine tuning of their pore architecture and their hydrophilic/hydrophobic character can improve their performance for technological or industrial applications. ${ }^{[4,16-24]}$ The geometrical constraints of the zeolitic framework can be proficiently exploited to induce the formation of nanostructured arrays with the desired dimensionality. Supramolecular materials which do not require chemical reactions to form composites such as dye-zeolite composites/artificial antenna systems in zeolite channels, ${ }^{[25-33]}$ biomolecules and chromophores immobilized in 1 -D channels, ${ }^{[34-4]}$ or low-dimensional nanoarchitectures of molecular clusters ${ }^{[42-44]}$ - have been successfully realized. The preparation of a continuous organic nanowire via a chemical reaction, i.e. polymerization reaction, would be of fundamental relevance in advanced materials fabrication. In fact, preparing isolated, self-standing, densely packed polymers, is extremely challenging when conventional protocols are adopted, since the aggregation and bending of chains prevent the 
production of real $1 \mathrm{D}$ systems. ${ }^{[45,46]}$ A possible solution could be the use of large-pore matrices as "microvessels" for conducting the polymerization reaction - such as mesoporous silicas/organosilicas ${ }^{[47,48]}$ and MOFs. ${ }^{[49]}$ On the other hand, zeolite cavities would be more suitable for small monomers, as the stricter space confinement might increase the degree of control on the polymer's structure. ${ }^{[50,51]}$ Indeed, by imposing pressure on zeolite systems, it is possible to induce a rearrangement of the chemical bonds among guest species hosted in the pores by purely mechanical tuning the intermolecular/interatomic distances via relatively high pressures (few GPa). Following this procedure, linear chains of polyethylene ${ }^{\left[{ }^{[2]}\right]}$ polyacetylene ${ }^{[53]}$ and polycarbonyl ${ }^{[54]}$ were synthesized inside zeolite channels and, very recently, phenylacetylene was oligomerized at high pressure inside the zeolite Mordenite (MOR). ${ }^{[55]}$ Differently, the formation of mixtures of long-chain polymers and small oligomers of pyrrole and thiophene were reported to occur inside transition-metal substituted zeolites, such e.g. $\mathrm{Cu}$ - or $\mathrm{Ni}$ - mordenites. ${ }^{[6,57]}$ Also, the presence of Brønsted acid sites ${ }^{[58-65]}$ could strongly affect the formation of a polymer inside the zeolite cavities: in particular, acid zeolites themselves can induce a polymerization reaction without the need of using high pressure and/or transition metals as catalysts. ${ }^{[46]}$ Overall, despite such a long-standing interest, the field of polymer/zeolite nanocomposites remains underexplored and yet underexploited. ${ }^{[66]}$

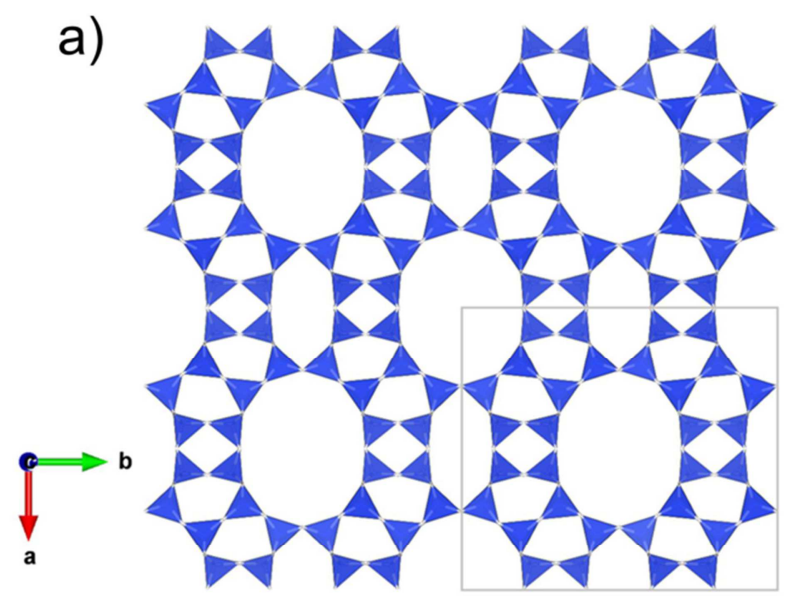

b)

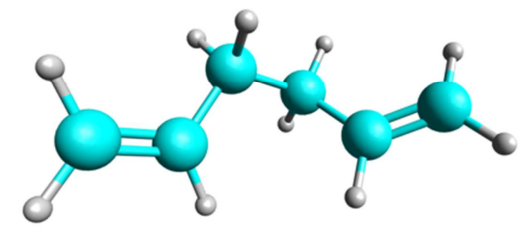

Figure 1. a) $H S-M O R$ framework structure viewed along the [ool] direction (the unit cell is drawn as grey solid lines); b) ball-and-stick representation of 1,5hexadiene. The length and the maximum diameter of the 1,5-hexadiene molecule (inclusive of van der Waals radii) are $9.5 \AA$ and $5.0 \AA$, respectively. ( $\mathrm{C}=$ cyan; $\mathrm{H}=$ white).

Here we investigate the feasibility of mild conditions zeoliteinduced polymerization adopting a highly flexible monomer in order to verify whether the zeolite channels shape could influence the structure of the final products. As host, we adopt a high silica
Mordenite zeolite (HS-MOR) (Figure 1a) - which can be viewed as formed by quasi-1D channels modulated by side pockets, ${ }^{[67]}$ while, as a flexible monomer, our choice falls on an $\alpha, \omega$-diene molecule - 1,5-hexadiene (also referred to as hexa, in the following) (Figure 1b). Indeed, in the absence of confinement, this molecule undergoes a series of complex reactions (e.g. Cope rearrangements, ${ }^{[68]}$ dimerizations, ${ }^{[69]}$ polymerizations ${ }^{[70]}$ ) characterized by intricate paths leading to a mixture of products. A regular polymer, using 1,5-hexadiene as a monomer, can be obtained only via a homogeneous Ziegler-Natta catalyst, leading to the formation of poly(methylene-1,3-cyclopentane) (PMCP). ${ }^{[1,72]}$ Even using homogeneous Ziegler-Natta-type catalysts with chiral ligands, achieving full control over the polymerization products is by no means straightforward: not only four microstructures of maximum order are possible for $\mathrm{PMCP}^{[70]}$, but also the formation of cross-linked polymers has been reported. ${ }^{[73]}$ Overall, selectivity and polymer morphology strongly depend on both the catalyst and the process conditions. ${ }^{[72,74,75]}$ Hence, 1,5-hexadiene clearly represents a challenging test for the "space-confining" effectiveness of zeolite channels over the possible reaction products and their morphology. Indeed, while the capability of zeolites to impose a well-defined supramolecular arrangement by forcing relatively weak intermolecular interactions is well known, here we explore whether such "molding" effects might be effective in dealing with processes requiring transformations of strong covalent bonds, like in a polymerization reaction.

\section{Results and Discussion}

\section{Basic investigation of the host steric constraints}

The target of our work is to probe the shape-directing capability of the mordenite framework towards the controlled reaction among 1,5-hexadiene molecules within its regular, empty-space architecture. In particular, we want to see if such a confining matrix could force these non-conjugate diene molecules to form a polymer. In this case, the structure of the encapsulated polymer should be sterically compatible with the geometric restrictions of the HS-MOR channels. Hence the first step of our work is to inspect the mordenite framework to understand if 1,5 -hexadiene based polymers could fit the zeolite mold.

The crystal structure of mordenite ${ }^{[76]}$ (framework type $\mathrm{MOR}^{[77]}$ ) is built up from an assembly of single 6-membered rings (6MR) forming sheets linked by single 4-membered rings (4MR) or else from a combination of 5-1 secondary building units. As shown in Figure 1a, MOR exhibits a $1 \mathrm{D}$ channel system resulting from two types of channels both running parallel to the $c$ axis: large 12MR channels ("free diameters" 6.5x7.0 Å) and strongly elliptic 8-membered rings (8MR) channels ("free diameters" 2.6x5.7 ̊̊). These channels are interconnected along the [o10] direction through side pockets delimited by $8 \mathrm{MRs}$ ' that, in turn, form a sinusoidal channel ("free diameters" 3.4 x 4.8 Å) running parallel to the $b$ axis. Only the main 12MR channels are accessible to hydrocarbon molecules. Mordenite has an orthorhombic unit cell with topological symmetry $\mathrm{Cmcm}$. The real symmetry is reduced to $\mathrm{Cmc2}_{1}{ }^{[78]}$ thus avoiding a straight linkage between tetrahedral $\mathrm{TO}_{4}$ units ( $\mathrm{T}-\mathrm{O}-\mathrm{T}$ angle, $\mathrm{T}=\mathrm{Si}, \mathrm{Al}$ ), but the crystal structure remains strongly pseudo-centrosymmetric. 
The sample used in this work is a commercial synthetic highsilica mordenite (HS-MOR; $S i / A l=200)$. The pristine material has been fully characterized and previously used in many studies, namely on the adsorption of pollutants from wastewaters, ${ }^{[78-80]}$ on the intrusion of ethylene glycol and water/alcohol mixtures at high pressure $(\mathrm{HP})^{[81]}$ and in the oligomerization of phenylacetylene at HP. ${ }^{[55]}$ Structural data and relevant details of the Rietveld refinements on the pristine $H S-M O R$ here used are reported in Table 1 , as well as those of the synthesized host-guest compound HS-MOR hexa, later discussed (the final observed and calculated powder patterns for HS-MOR hexa are provided in the Supporting Information, Figure $1 S$; atomic coordinates, occupancy factors, thermal parameters and selected bond distances $(\AA)$ are reported in Tables $1 S$ and $2 \mathrm{~S}$, respectively).

Table 1. Structural parameters of $H S-M O R$ and HS-MOR hexa and refinement parameters of HS-MOR hexa.

\begin{tabular}{lll}
\hline & $H S-M O R^{[\mathrm{a}]}$ & HS-MOR hexa ${ }^{[\mathrm{b}]}$ \\
\hline Space group & $C m c m$ & $C m c m$ \\
$\mathrm{a}(\AA)$ & $18.0519(8)$ & $18.0563(4)$ \\
$\mathrm{b}(\AA)$ & $20.2061(8)$ & $20.2346(4)$ \\
$\mathrm{c}(\AA)$ & $7.4506(3)$ & $7.4524(1)$ \\
$\mathrm{V}\left(\AA^{3}\right)$ & $2717 \cdot 7(2)$ & $2722.82(7)$ \\
$\mathrm{H}_{2} \mathrm{O}$ molecules p.u.c. & 3.6 & 3.5 \\
from refinement & & \\
$\mathrm{R}_{\mathrm{wp}}(\%)$ & & 5.32 \\
$\mathrm{Rp}(\%)$ & 3.05 \\
$\mathrm{RF}^{2}(\%)$ & 11.75 \\
$\mathrm{~N}_{\text {obs }}$ & & 854 \\
$\mathrm{~N}_{\text {var }}$ & & 71 \\
\hline
\end{tabular}

[a] From Ref. ${ }^{[81]}$. [b] This work.

The 1,5-hexadiene molecule (Figure $1 \mathrm{~b}$ ), which has a maximum diameter of $5.0 \AA$, is size-compatible with the 12MR channels and may be incorporated inside the $H S-M O R$ framework. However, could 1-D oligomers/polymers composed by 1,5 -hexadiene molecules be also compatible with the HS-MOR channels? To tackle this question, we considered the following models of continuous 1-D hexa polymers, depicted in Figure 2, which might all in principle fit to the $12 \mathrm{MR}$ channels:

- model A: a simple alkyl chain (of the poly(methylene) type), with no side moieties

- model B: a polymer with side chain constituted by a propyl group which penetrates inside the side pockets of MOR

- model C: a 1-D chain of (non-aromatic) 5-membered rings (cyclopentane), representative of a regular poly(methylene-1,3 cyclopentane) polymer

- model D: a chain containing cyclopentane units and lateral ethyl groups

- model E: a chain containing cyclopentane units and side vinyl groups.

The next step would be to examine whether any of these putative models could be representative of a low- dimensionality polymer formed upon the incorporation of 1,5-hexadiene molecules in HS-MOR. We address this issue by means of multi-technique analyses, aimed at a closer characterization of the chemical features of the zeolite matrix.

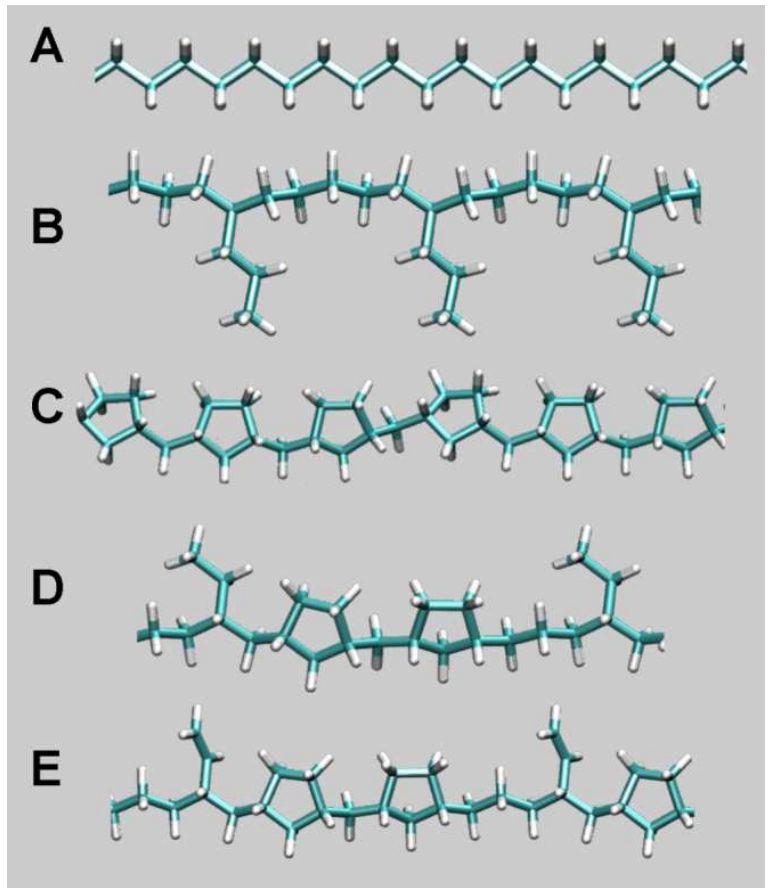

Figure 2. Graphical representation of the model 1-D-polymers A-E. Color codes: $\mathrm{C}=$ cyan; $\mathrm{H}=$ white.

Chemical features of HS-MOR as revealed by IR spectroscopy of adsorbed $\mathrm{NH}_{3}$

In order to probe the chemical features of $H S-M O R$, the adsorption of $\mathrm{NH}_{3}$ was carried out and monitored by IR spectroscopy. Figure 3 shows the spectra of $H S-M O R$ outgassed at room temperature (r.t.), and in contact with $\mathrm{NH}_{3}$ at the pressure of 2 mbar. As demonstrated in previous work, ${ }^{[82]}$ outgassing at r.t. (curve a) allowed the complete desorption of water molecules originally present in the zeolite channels, thus the signals present in the $3800-3000 \mathrm{~cm}^{-1}$ range are overwhelmingly due to the $\mathrm{vOH}$ mode of silanols, framework Si-OH-Al and extraframework Al$\mathrm{OH}$ species being a minor feature. Silanols involved in H-bonding, as in the so-called "silanol nests", are responsible for the broad component spread over the $3650-3000 \mathrm{~cm}^{-1}$ range (maximum out of scale), while $\mathrm{SiOH}$ involved in progressively weaker interactions produce the signals at higher frequency, with maxima at 3682 and $3730 \mathrm{~cm}^{-1}$. 


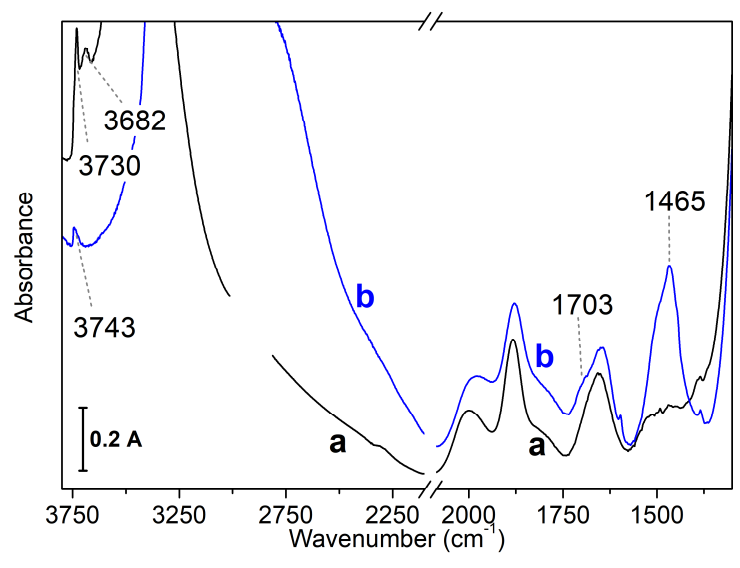

Figure 3. IR spectra of $H S-M O R$ : a) after outgassing at r.t. for $1 \mathrm{~h}$; b) after the admission of $\mathrm{NH}_{3}$, at $\mathrm{p}=2$ mbar.

Below $2000 \mathrm{~cm}^{-1}$, a triplet is present, due to combinations (2000 and $\left.1882 \mathrm{~cm}^{-1}\right)$ and an overtone $\left(1654 \mathrm{~cm}^{-1}\right)$ of framework modes (absorbing below the low-frequency transparency limit imposed by the use of a self-supporting pellet, ca. $\left.1300 \mathrm{~cm}^{-1}\right)$. The adsorption of $\mathrm{NH}_{3}$ molecules (curve b) results in a change in the refractive index of the zeolite grains, with the consequent change in the scattering profile (different slope of the baseline, in a larger extent in the $3800-2400 \mathrm{~cm}^{-1}$ range). Focusing on the absorption spectral features, $\mathrm{vOH}$ signals due to silanols appeared downshifted, now contributing to a very broad and intense (maximum out of scale) absorption in the $3670-2400 \mathrm{~cm}^{-1}$ range, where also $v \mathrm{NH}$ components due to adsorbed $\mathrm{NH}_{3}$ molecules should be present. The increase in the absorption intensity at about $1650 \mathrm{~cm}^{-1}$ is consistent with the appearance of an additional contribution due to the antisymmetric deformation mode of $\mathrm{NH}_{3}$ molecules in interaction with silanols. ${ }^{\left[{ }^{3}\right]}$ Noteworthy, the main difference with respect to the spectrum of the bare zeolite is the appearance of components at 1703 (shoulder) and $1465 \mathrm{~cm}^{-1}$, due to the deformation modes of $\mathrm{NH}_{4}^{+}$adducts, resulting from a proton transfer from the very minor canonical $\mathrm{Si}-\mathrm{OH}-\mathrm{Al}$ Brønsted sites possibly present and from silanols to adsorbed ammonia molecules. Indeed, cooperative effects occurring among $\mathrm{SiOH}$ in silanol nests have been proposed to increase the acidity of some silanols, becoming able to transfer their proton to sufficiently nucleophilic adsorbed molecules. ${ }^{[84,85]}$

\section{Reactivity of 1,5 -hexadiene in $H S$-MOR as revealed by IR spectroscopy}

The loading of 1,5-hexadiene in HS-MOR was monitored by in situ IR spectroscopy and the final sample was later used for thermogravimetry and the XRPD analyses.

Figure 4 shows the IR spectra of 1,5-hexadiene adsorbed on HS$M O R$ pre-outgassed at r.t. (curve a), and the subsequent evolution as a function of contact time (curves b,c). The spectrum of the molecule in the gas phase (curve a') is reported for comparison. The assignment of the signals of the molecule in this form, as well as the beginning of the contact with $H S-M O R$, and along contact time is reported in Table 2. As a consequence of the interaction with the zeolite, the frequency of the modes producing signals in the accessible range is downshifted of few wavenumbers, but the main distinctive aspect is constituted by the appearance of additional bands at 1525 and $1380 \mathrm{~cm}^{-1}$, and a shoulder at $1465 \mathrm{~cm}^{-1}$. These signals are assignable to the $\mathrm{C}-\mathrm{C}$ stretching of allylic carbocation species, the symmetric deformation mode $\left(\delta_{\mathrm{s}} \mathrm{CH}_{3}\right)$ and the antisymmetric one $\left(\delta_{\mathrm{as}} \mathrm{CH}_{3}\right)$ of $-\mathrm{CH}_{3}$ groups, respectively. ${ }^{[86,87]}$ Partner $\mathrm{C}-\mathrm{H}$ stretching modes of the methyl groups are expected at higher frequency, where they should contribute as minor, unresolved components to the spectral pattern in the $3000-2800 \mathrm{~cm}^{-1}$ range due to stretching modes of $\mathrm{CH}_{2}\left(\mathrm{sp}^{2}\right)$ and $-\mathrm{CH}_{2}\left(\mathrm{sp}^{3}\right)$. The presence of these additional signals indicates that a proton transfer occurred from the zeolite to adsorbed molecules. Moreover, the formation of allyl carbocation species can be explained in terms of an initial protonation of one of the terminal $\mathrm{C}=\mathrm{C}$ bonds, followed by a migration of the positive charge along the carbon atom chain towards the other terminal $\mathrm{C}=\mathrm{C}$, where the carbocations can experience resonance stabilization by delocalization of the positive charge to the adjacent $\pi$ bond $\left(\mathrm{R}-\mathrm{C}(+) \mathrm{H}-\mathrm{CH}=\mathrm{CH}_{2} \leftrightarrow \mathrm{R}-\mathrm{CH}=\mathrm{CH}-\mathrm{C}(+) \mathrm{H}_{2}\right)$. Such a reactivity proceeded along the first hour of contact (curves $b$ ), as monitored by a decrease in intensity of the $v(C=C)$ band $\left(1641 \mathrm{~cm}^{-}\right.$ $\left.{ }^{1}\right)$ and of signals related to $-\mathrm{CH}_{2}\left(\mathrm{sp}^{2}\right)\left(3083,2980,1417 \mathrm{~cm}^{-1}\right)$ and $\mathrm{CH}\left(\mathrm{sp}^{2}\right)\left(3007 \mathrm{~cm}^{-1}\right)$, accompanied by an increase in the intensity of the band due to allylic carbocations $\left(\mathrm{ca}, 1525 \mathrm{~cm}^{-1}\right)$ and $-\mathrm{CH}_{3}$ groups $\left(2961,2873,1465\right.$ and $138 \mathrm{o} \mathrm{cm}^{-1}$ ) (details on the assignment in Table 2). For longer contact time, the static condition entails the partial rehydration of the system by water molecules unavoidably remained adsorbed on the inner walls of the IR cell even after the initial outgassing at r.t., and $\mathrm{H}_{2} \mathrm{O}$ stretching and bending modes interfere with the observation of the evolution of the $-\mathrm{CH}_{\mathrm{x}}\left(\mathrm{sp}^{2}\right.$ and $\left.\mathrm{sp}^{3}\right)$ and $\mathrm{C}=\mathrm{C}$ signals (Figure $\mathrm{S}$, see Supporting Information). After one week of contact, water molecules were removed by outgassing at r.t. and the whole spectral profile due to organic species became observable (curves c), revealing a strong decrease in intensity of the $-\mathrm{CH}_{2}\left(\mathrm{sp}^{2}\right)$ and $-\mathrm{CH}\left(\mathrm{sp}^{2}\right)$ signals, in favor of those due to $-\mathrm{CH}_{3}$ groups. An evolution of the band assigned to allylic carbocations also occurred: the signal initially at $1525 \mathrm{~cm}^{-1}$ is converted in a complex pattern at lower frequency, constituted by at least three components, the most intense of them being located at $1498 \mathrm{~cm}^{-1}$. Such a behavior can be due to some change in the interaction with the zeolite lattice, in terms of interaction strength and of a possible heterogeneity of zeolite sites acting as anions.

In summary, the set of IR data allows inferring that 1,5-hexadiene molecules in $H S-M O R$ participate in carbocation-based reactions that, on the basis of the $80 \%$ decrease in intensity of the $v(C=C)$ signal $\left(1641 \mathrm{~cm}^{-1}\right)$, involve the large majority of monomers. 


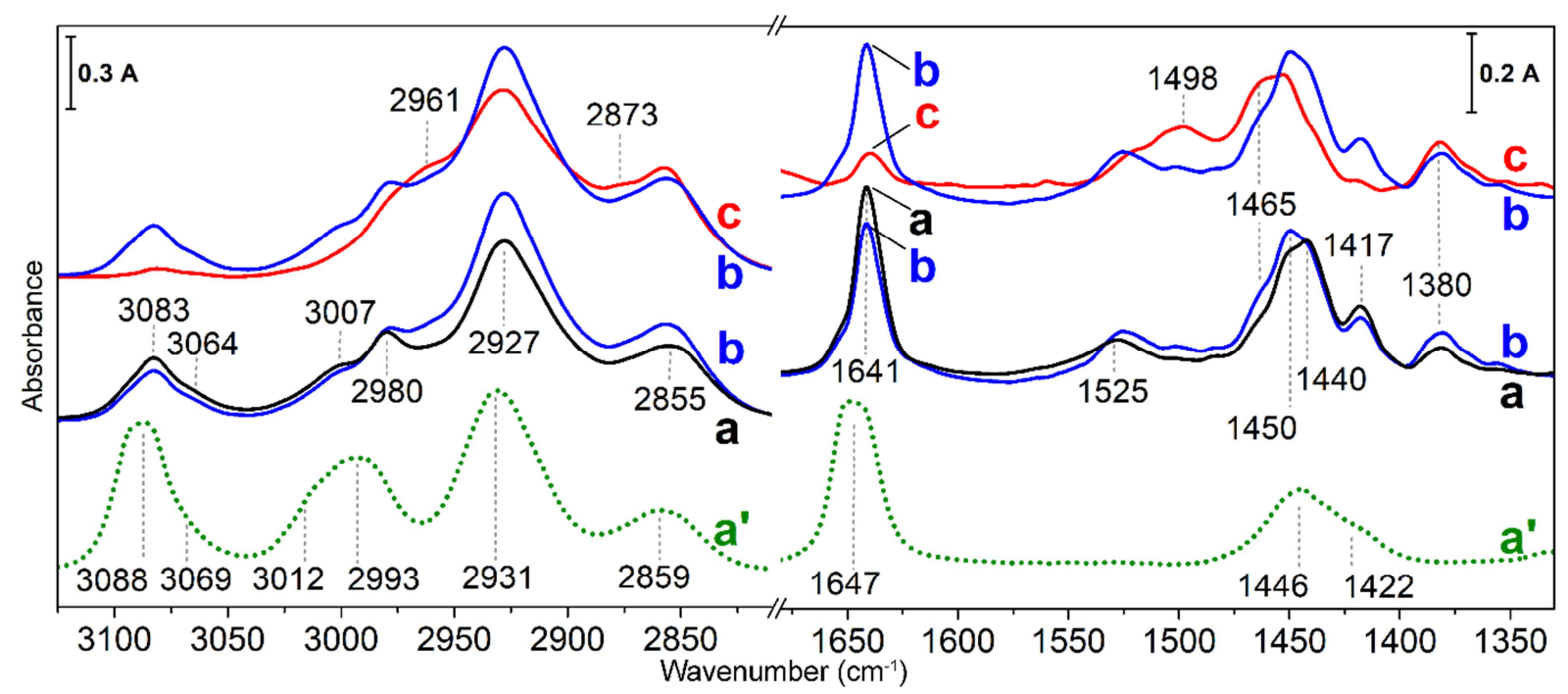

Figure 4. IR spectra of 1,5-hexadiene: a') in vapor phase, at $\mathrm{p}=25 \mathrm{mbar}$; a) immediately after contact with $H S$-MOR (pre-outgassed ar r.t. for 1 h), at $\mathrm{p}=50 \mathrm{mbar}$; ) after $\mathrm{ih}$ of contact; c) after 1 week of contact, and outgassing at r.t. for $1 \mathrm{~h}$. Spectra a-c are reported as resulting from the subtraction of the spectrum of $H S$-MOR prior 1,5 -hexadiene adsorption. Spectrum b is shown in duplicate, for the sake of comparison with spectrum c.

Table 2. Assignment of 1,5-hexadiene infrared absorptions

$$
\text { mode }
$$

\begin{tabular}{|c|c|c|c|}
\hline \multirow[t]{2}{*}{ mode } & \multicolumn{3}{|c|}{ Frequency $\left(\mathrm{cm}^{-1}\right)$} \\
\hline & $\begin{array}{c}\text { gas phase } \\
(\mathrm{p}=10 \mathrm{mbar})\end{array}$ & $\begin{array}{c}\text { HS-MOR hexa } \\
\text { (immediately } \\
\text { after adsorption) }\end{array}$ & $\begin{array}{l}\text { HS-MOR hexa } \\
\text { (new signals } \\
\text { rising during } \\
\text { time evolution) }\end{array}$ \\
\hline
\end{tabular}

\begin{tabular}{|c|c|c|c|}
\hline$v_{\mathrm{as}} \mathrm{CH}_{2}\left(\mathrm{sp}^{2}\right)$ & 3088 & 3083 & 3080 \\
\hline $\begin{aligned} \mathrm{vC}=\mathrm{C}+\delta_{\mathrm{ip}} \mathrm{CH}_{2} \\
\left(\mathrm{sp}^{2}\right)^{\left[{ }^{*}\right]}\end{aligned}$ & 3069 & 3066 & \\
\hline$v \mathrm{CH}\left(\mathrm{sp}^{2}\right)$ & 3012 & 3007 & \\
\hline$v_{\mathrm{s}} \mathrm{CH}_{2}\left(\mathrm{sp}^{2}\right)$ & 2993 & 2980 & \\
\hline $\mathrm{v}_{\mathrm{as}} \mathrm{CH}_{3}$ & & & 2961 \\
\hline$v_{\mathrm{as}} \mathrm{CH}_{2}\left(\mathrm{sp}^{3}\right)$ & 2931 & 2927 & \\
\hline $\mathrm{v}_{\mathrm{s}} \mathrm{CH}_{3}$ & & & 2873 \\
\hline$v_{\mathrm{s}} \mathrm{CH}_{2}\left(\mathrm{sp}^{3}\right)$ & 2859 & 2855 & \\
\hline$v C=C$ & 1647 & 1641 & \\
\hline$\delta_{\mathrm{as}} \mathrm{CH}_{3}$ & & & 1465 \\
\hline$\delta \mathrm{CH}_{2}\left(\mathrm{sp}^{3}\right)$ & $\begin{array}{c}\text { (unresolved) } \\
1446\end{array}$ & 1450 & \\
\hline$\delta \mathrm{CH}_{2}\left(\mathrm{sp}^{3}\right)$ & $\begin{array}{c}\text { (unresolved) } \\
1446\end{array}$ & 1440 & \\
\hline$\delta_{\mathrm{ip}} \mathrm{CH}_{2}\left(\mathrm{sp}^{2}\right)$ & 1422 & 1417 & \\
\hline$\delta_{\mathrm{s}} \mathrm{CH}_{3}$ & & & 1380 \\
\hline
\end{tabular}

as: antisymmetric; s: symmetric; ip: in plane

[*] From ref. ${ }^{[88]}$ The other assignments are from ref. ${ }^{\left[{ }^{[8]}\right.}$

\section{1,5-hexadiene in HS-MOR: quantitative aspects}

To gather a quantitative estimation of the guest species contained in the zeolite porosities, we performed thermal analyses on the sample after completion of the reactive processes, using as a reference the unloaded zeolite. Figure 5 shows the thermal gravimetric analysis (TGA) and the corresponding differential thermogravimetry curve of $H S-M O R$ and of HS-MOR hexa after one week of reaction (i.e. sample in spectrum c in Figure 4). When loaded in the TGA cell, both samples were exposed to air. Below $200{ }^{\circ} \mathrm{C}$, the unloaded $H S-M O R$ (curves a and a') shows a first weight loss (1.9 wt.\%) in two distinguishable steps accounting for superficial water and water loosely adsorbed within the channels. A second weight loss of 2 wt.\% occurs in the $400-800{ }^{\circ} \mathrm{C}$ range, in good agreement with the silanol condensation process discussed by Fantini et al. ${ }^{\left[8_{2}\right]}$

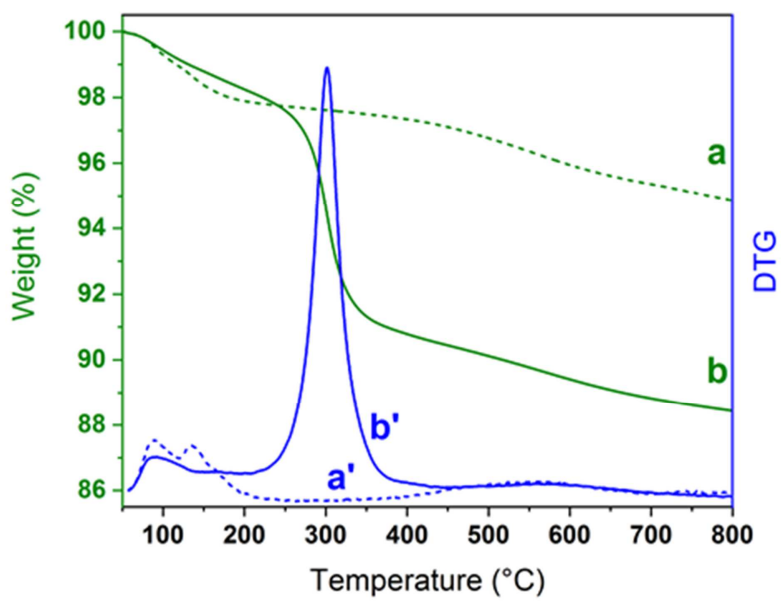

Figure 5. TG (green) and DTG curves (blue) for of HS-MOR (a, a') and HS-MOR hexa (b, b'). 
The HS-MOR hexa (curves b and b') sample shows a reduced weight loss of 1.5 wt.\% below $200{ }^{\circ} \mathrm{C}$ which can be justified by a lesser quantity of water molecules within the zeolite channels, likely due to the presence of co-hosted hexa molecules. Confirmatory evidence of the decrease in water content of HS-MOR hexa was provided by XRPD data analysis (vide infra). The main weight loss of $7.5 \mathrm{wt} . \%$ occurs in the $200-450{ }^{\circ} \mathrm{C}$ range, suggesting a unique process for the release of all the organic moieties. Above $450{ }^{\circ} \mathrm{C}$, also in this sample, a further weight loss of $1.8 \mathrm{wt} . \%$ due to the condensation of silanols is observed.

As a whole, considering the number of hydroxyls in the HS-MOR to be constant before and after the hexa loading, the weight loss due to organic moieties corresponds to the presence, on an average, of ca. 2.9 hexa molecules per unit cell, i.e. ca. 1.5 molecules per each of the two 12 MR channels in a unit cell. Thus, the reaction evidenced by IR spectroscopy not only involved most of the 1,5-hexadiene molecules, but it also took place within the majority of the zeolite porosity, as also further substantiated by the structural analysis.

\section{1,5-hexadiene in HS-MOR: experimental structural aspects}

From the XRPD patterns reported in Figure 6, it is possible to observe differences in the relative intensities of low angle peaks of $H S-M O R$ and HS-MOR hexa samples. This is a clear indication of the penetration of 1,5 -hexadiene molecules in the zeolite pores, partially occupied by only $\mathrm{H}_{2} \mathrm{O}$ molecules in the pristine sample, as found in the case of phenylacetylene. ${ }^{[5]}$

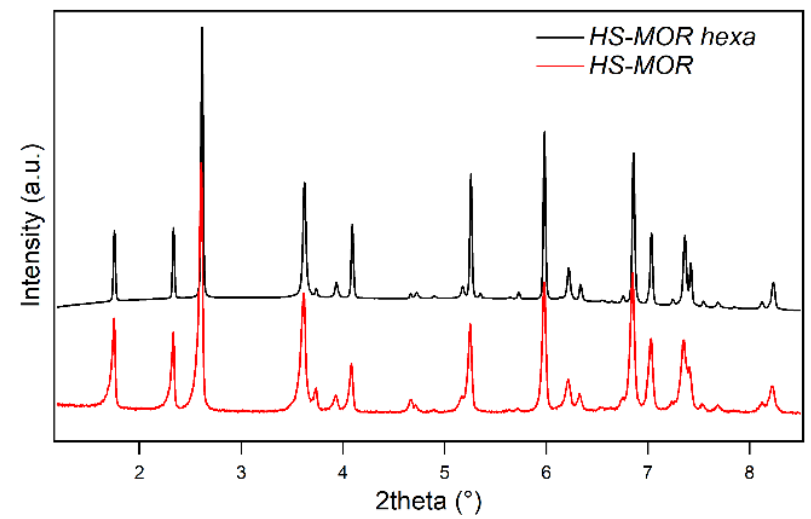

Figure 6. Comparison of the XRPD patterns of $H S-M O R^{\left[8_{1}\right]}$ and $H S-M O R$ hexa The two patterns have been rescaled and normalized for the same intensity on the third peak, at $2.6^{\circ}$. Selected 2 theta range is reported, full patterns are reported in Figure $2 \mathrm{~S}$

Upon the inspection of the difference Fourier map, it was possible to locate a chain composed by six carbon atoms in the $12 \mathrm{MR}$ channel, as reported in Figure 7 , that lies on the plane perpendicular to [100]. The carbon atoms forming the chain occupy two crystallographic positions $C_{1}$ and $C_{2}$ (with an average C-C distance $\sim 1.5 \AA$ ) accounting for 2 and 4 carbon atoms in each channel of the unit cell, respectively. As a whole, based on the $C$ sites multiplicity and on their full occupation, twelve $C$ atoms are hosted in each unit cell - that is, one six membered chain per channel (i.e. two six membered chain p.u.c.) whose axis coincides with the [oo1] direction. Noteworthy, residual maxima are present in the Fourier map located around the chain (Figure $7 \mathrm{~b}-\mathrm{c}$ ), suggesting that side moieties could be present in the side pockets as well, in a disordered arrangement.

This observation provides evidence that sub-sets of the six membered $C$ atoms chain should derive from different 1,5-hexadiene molecules. The average distance of $\sim 1.5 \AA$ between C-C atoms (see Table S2) indicates the formation of a continuous $\mathrm{C}$ atom chain running along the $12 \mathrm{MR}$ channel (Figure $7 \mathrm{a}$ ). The full occupancy of all the carbon sites indicates an extended polymerization reaction of the 1,5-hexadiene molecules into the channels, in agreement with the IR results. It is worth noting that, since the de-alumination procedure - aimed at the obtainment of a high silica phase - induces strong defectivity, the starting zeolite presents a certain degree of mesopores and defects. ${ }^{[55]}$ We can assume that the detected chain occupies basically the ordered microporous volume of the sample.
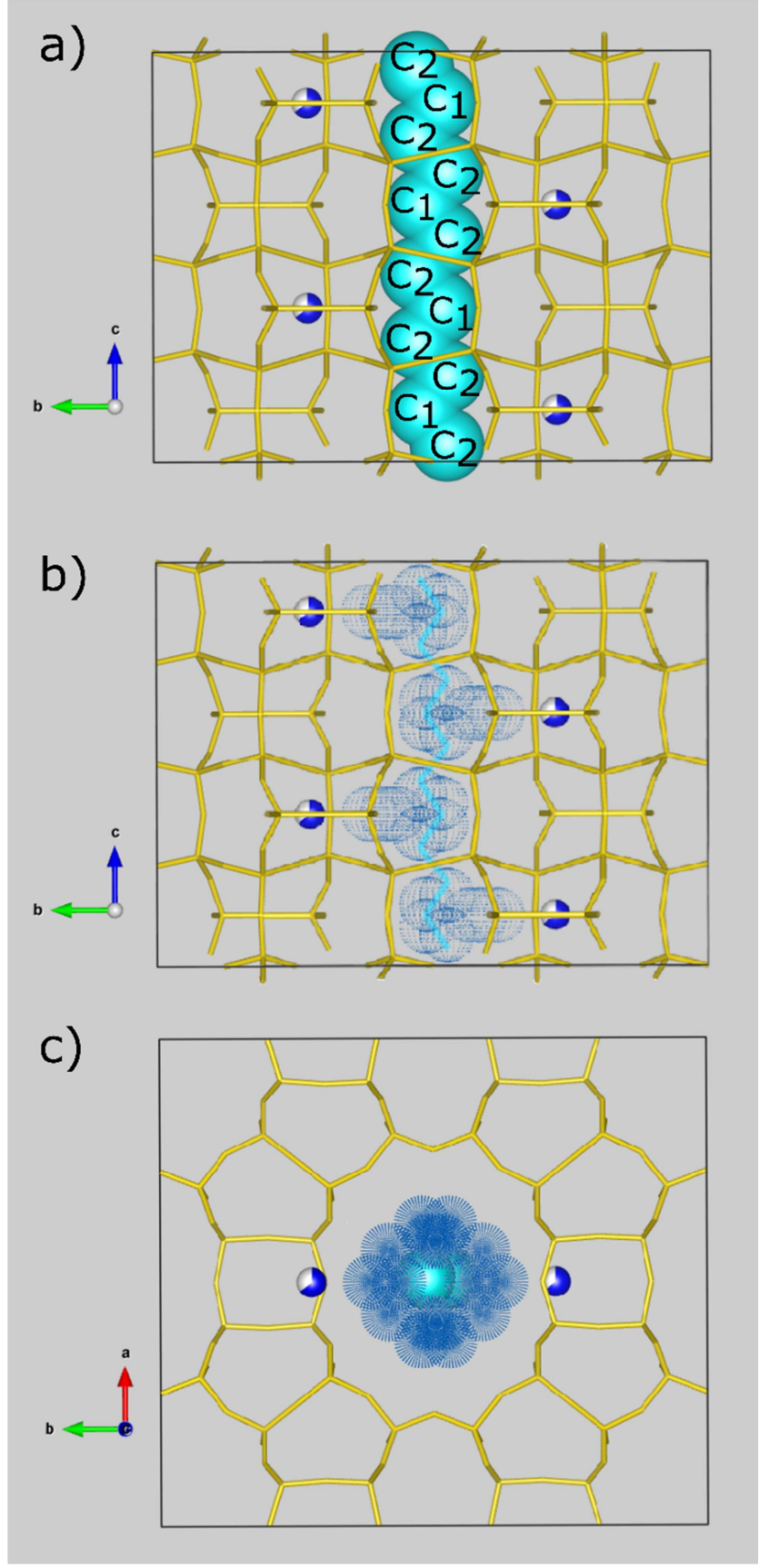
Figure 7. Details of $H S-M O R$ hexa structure, data obtained by XRPD structural refinement. Water molecules are represented in blue, while carbon atoms are in cyan. For clarity, just the extraframework content occupying the central channel is reported. a) HS-MOR hexa structure reported along [10o] direction b) $H S$ MOR hexa structure reported along [100] direction showing the residual maxima (blue clouds) of the Fourier map positioned around the $\mathrm{C}_{1}-\mathrm{C}_{2}$ chain (in cyan) c) HS-MOR hexa structure reported along [0o1] direction showing the residual maxima (blue clouds) of the Fourier map positioned around the $\mathrm{C}_{1}-\mathrm{C}_{2}$ chain (in cyan).

An additional peak of the difference Fourier map was ascribed to a $\mathrm{H}_{2} \mathrm{O}$ molecule site in the window between the $12 \mathrm{MR}$ and the side pocket, corresponding to the $\mathrm{W}_{1}$ site found in the pristine sample. $^{\left[{ }^{81}\right]}$

The refinement of the occupancy factor leads to a total $\mathrm{H}_{2} \mathrm{O}$ amount of 3.5 molecules per unit cell. This is in agreement with the results of the thermal analysis, indicating a water content of about 2.6 molecules per unit cell (corresponding to $1.5 \mathrm{wt} \%$ ). The water present in the channel is re-adsorbed once the sample is recovered in air after the 1,5 -hexadiene loading.

After 1,5-hexadiene reaction, the cell parameters of the loaded sample show only a slight increase, mainly related to the lengthening of the $b$ parameter. In fact, once the hexa molecules are hosted in the zeolite pores, the channels adapt to the new host: the 12MR channel becomes more circular and, as a consequence, the 8MR channel further lengthens along $a$ direction. The lengthening of the $b$ parameter is mainly due to the rotation of the $\mathrm{Si}_{3}$ and $\mathrm{Si}_{4}$ tetrahedra belonging to the $4 \mathrm{MR}$ ring (Table 3 and Figure 8).

Table 3. $12 \mathrm{MR}$ and 8MR channel diameters and angles of $H S-M O R^{\left[8_{1}\right]}$ and $H S$ MOR hexa. The ellipticity parameters $\mathrm{E}$ is defined as the ratio between the largest and the smallest O-O diameters, the Crystallographic Free Area (CFA) is also reported.

\begin{tabular}{|c|c|c|}
\hline & $H S-M O R^{[a]}$ & $H S-M O R$ hexa $a^{[b]}$ \\
\hline \multicolumn{3}{|l|}{ 12MR } \\
\hline $\mathrm{O}_{7}-\mathrm{O}_{7}$ & 10.02 & $9.81(3)$ \\
\hline Oı-O10 & 8.85 & $8.86(5)$ \\
\hline E & 1.13 & 1.11 \\
\hline CFA $\left(\AA^{2}\right)$ & 35.1 & \\
\hline \multicolumn{3}{|l|}{ 8MR } \\
\hline $\mathrm{O}_{7}-\mathrm{O}_{7}$ & 8.03 & $8.25(3)$ \\
\hline $\mathrm{O}_{9}-\mathrm{O}_{9}$ & $5 \cdot 58$ & $5 \cdot 52(4)$ \\
\hline $\mathrm{E}$ & 1.44 & 1.5 \\
\hline CFA $\left(\AA^{2}\right)$ & 10.61 & \\
\hline \multicolumn{3}{|l|}{${ }_{4} \mathrm{MR}$} \\
\hline $\mathrm{O}_{9}-\mathrm{O} 10$ & 4.01 & $4.06(3)$ \\
\hline $\mathrm{O}_{4}-\mathrm{O}_{4}$ & $3 \cdot 35$ & $3.33(3)$ \\
\hline $\mathrm{O}_{4}-\mathrm{O}_{10}-\mathrm{O}_{4}$ & 77.82 & $77.029(2)$ \\
\hline $\mathrm{O}_{9}-\mathrm{O}_{4}-\mathrm{O}_{10}$ & 100.28 & $100.808(2)$ \\
\hline
\end{tabular}

[a] From Ref. ${ }^{\left[8_{1}\right]}$. [b] This work. ...
This mechanism induces the lengthening of the O9-Oro distance, oriented along $b$. Conversely, the O10-O1o diameter of the 12MR channel remains almost unchanged, due to the steric hindrance of the organic chain lying on the $b c$ plane. The polymer chain weakly interacts with the framework oxygen O1o, as suggested by the C2-O1o distance equal to about $3.6 \AA$ (Table $2 \mathrm{~S}$, Supporting Information).

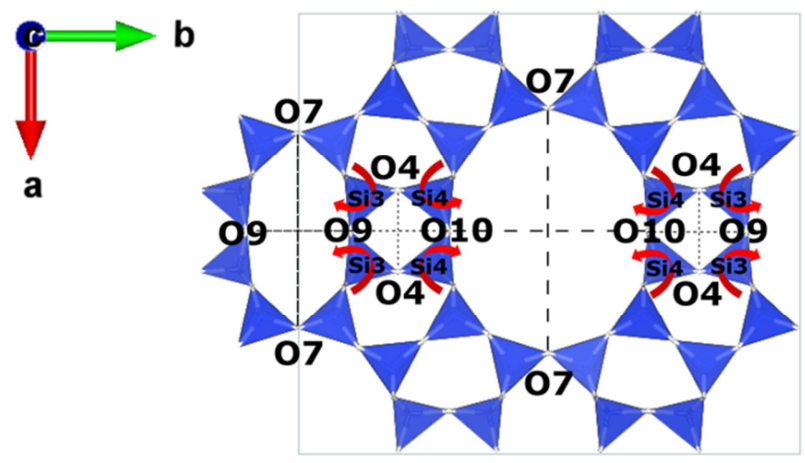

Figure 8. Mechanism of cell adapting due to the polymer formation: the $12 \mathrm{MR}$ channel becomes more circular and, as a consequence, the $8 \mathrm{MR}$ channel further lengthens along $a$ direction.

\section{Modeling of 1,5-hexadiene reacted in $H S$-MOR}

The features emerging from the above-presented spectroscopic, thermogravimetric and structural data could only provide an average picture of the composite system. A microscopic insight required the following computational analyses. Figure 9 depicts the optimized structures of the five different model polymers considered in our study, presented at the beginning of this Section, and now located within the zeolite 12 MR channels. They constitute a representative sample of the possible ways in which 1,5-hexadiene molecular units could be assembled into a continuous 1-D structure incorporated in HS-MOR.

It is apparent that all model polymers are compatible with the geometric restrictions of the zeolite channels. Most importantly, calculations indicate that they are all stabilized by the zeolite framework. Specifically, the $H S-M O R /$ polymer binding energies are $-29.65,-41.64,-43.60,-40.07,-38.80 \mathrm{kcal} \mathrm{mol}^{-1}$ per simulation cell (p.s.c.) for Models A, B, C, D, E, respectively.

Such an ordering of the binding energies can be understood by considering the nature of the dominant host-guest interactions.

The composition of the polymers and the HS-MOR framework indicates that the host-guest interactions in these composites should be essentially of the van der-Waals type. Accordingly, the model having, by far, the smallest binding energy is Model A which contains the simple 1,5-hexadiene derived polymer without side moieties (poly(methylene)), eventually resulting from a head-tail reaction for all molecules. The stabilizing effect of the zeolite framework is lowest for this composite because Model A exhibits the largest separation between the polymer chain and the zeolite walls (minimum C-O framework distance $=3.85 \AA$ ). In contrast, the minimum $\mathrm{C}-\mathrm{O}_{\text {framework }}$ distances exhibited by the other models are considerably shorter (3.18 $\AA$, 3.31 $\AA$, 3,24 $\AA$, and $3.28 \AA$ for Models B, C, D, E, respectively) and well in line with the values found for other bulky organic species encapsulated in zeolite channels. ${ }^{[28,31,89-94]}$ 

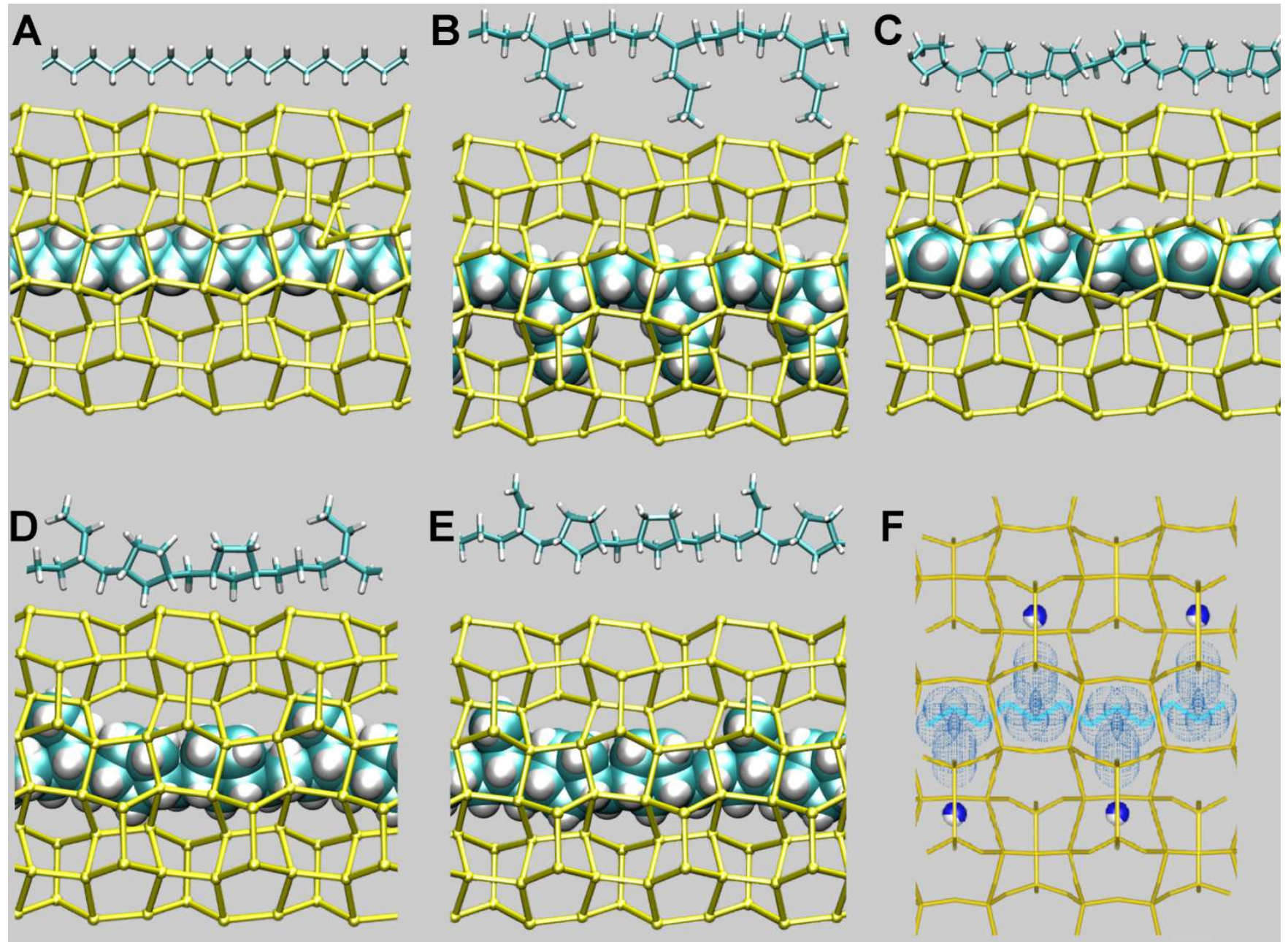

Figure 9. A-E): Graphical representation of the optimized structures of HS-MOR encapsulating: Model A) linear, non-branched alkyl polymer chain; Model B) chain with side propyl groups penetrating in the MOR side pockets; Model C) all-cyclopentane-chain featuring a PMCP polymer; Model D) chain containing two cyclopentane units and one branching ethyl group p.s.c.; Model E) chain containing two cyclopentane units and one branching vinyl group p.s.c.. The five 1,5-hexadiene based polymer chains inside the HS-MOR framework are highlighted in van-der-Waals representation. For each model composite, the correspondent polymer chain is also shown on top of the composite in stick representation. All the five polymer chains are stabilized by the HS-MOR framework. Color codes: HSMOR framework=yellow; $\mathrm{C}=$ cyan; $\mathrm{H}=$ white. $\mathrm{F}$ ): $H S$-MOR hexa structure showing the residual maxima of the Fourier map positioned around the $\mathrm{C}_{1}-\mathrm{C}_{2}$ chain (color codes as in Figure $7 \mathrm{~b})$. All structures are projected in the bc plane.

Hence, Model A could be considered as the least probable structure among the five models. This hypothesis is also in line with the IR data, which evidenced an appreciable proportion of terminal methyl groups. Indeed, Model B - which features side propyl groups hosted in the HS-MOR side pockets - is considerably more favorable as its binding energy p.s.c. is about 12 Kcal mol ${ }^{-1}$ greater than Model A.

Among the five models, Model $\mathrm{B}$ exhibits the shortest minimum C-O $\mathrm{O}_{\text {frame }}$ distance $(3.18 \AA)$, which is related to the partial penetration of the propyl side chain in the MOR side pockets (Figure $9 b$ ). Model C contains a 1-D chain of cyclopentane units, known as poly(methylene-1,3 cyclopentane). This polymer was identified as a maximum-order product of the polymerization of 1,5-hexadiene in presence of homogeneous Ziegler-Natta catalysts. ${ }^{[0,95,96]}$ In our case, Model C exhibits the greatest binding energy among the five models, likely because of the optimal hostguest contacts inside the HS-MOR main channels. The 1-D cyclopentane chain perfectly fits into the $12 \mathrm{MR}$ void space, so maximizing the favorable van-der-Waals interactions with the host without inducing significant distortion of the HS-MOR framework.

On the other hand, the IR evidence of terminal methyl groups suggests that the ideal polycyclopentane chain in Model C should be less likely than a branched polymer. Hence Model D - which features both branching alkyl groups and cyclopentane units might be a more realistic model of the polymer chain inside MOR: its binding energy is comparable to Models B and C, and the ethyl branching group can be well accommodated inside the main channel of the host. Finally, Model E contains a branching vinyl group, and it is structurally and energetically very close to Model D. Since the IR analyses indicate that the almost complete loss of the double $\mathrm{C}=\mathrm{C}$ bonds signals occurs over a very long time (about a week), Model E might actually represent a possible model for the 1-D chain which still contains some unreacted double bonds. 
A visual comparison of Models A-E with panel F in Figure 9 suggests that some of these models might be representative of the refined structure. To establish which of the five models better compares with the XRPD data, we superposed the symmetrized structure of each model to the refined structure.

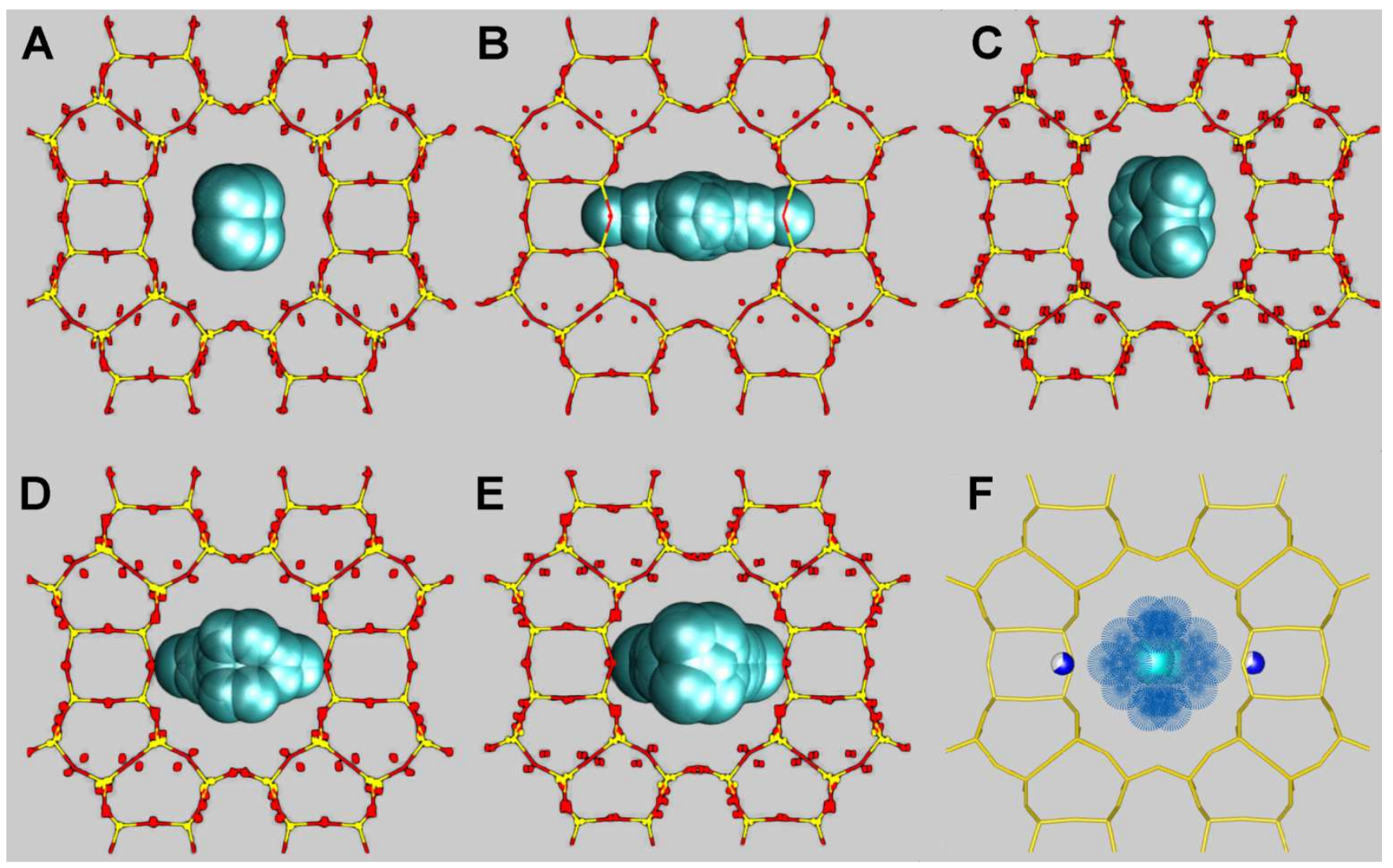

Figure 10. A-E): Symmetrized optimized structures of Models A-E projected in the ab plane ( $\mathrm{Si}, \mathrm{O}=$ dots; $\mathrm{C}=$ van der Waals spheres) superposed on the XRPD structure of the framework (represented as sticks). The symmetrized optimized structures were obtained by applying the symmetry operations of the Cmcm space group of HS-MOR to the optimized atomic positions of each model. Color codes: $\mathrm{Si}=$ yellow; $\mathrm{O}=\mathrm{red}$; $\mathrm{C}=$ cyan. F): XRPD structure of $H S-M O R$ hexa also showing the residual maxima of the Fourier map positioned around the $\mathrm{C}_{1}-\mathrm{C}_{2}$ chain (color codes as in Figure $7 \mathrm{c}$ ).

To perform the comparison, we applied to the calculated atomic positions of our models the symmetry operations of the $\mathrm{Cmcm}$ group. As well known, the refined structure of the composite actually results from averaging over a number of different configurations characterized by a symmetry lower than that of the ideal zeolite framework. ${ }^{[1]}$ Indeed, figures 1oa-e clearly show that the computed positions of the framework atoms are symmetrically distributed around the lines denoting the refined structure. In line with results obtained on other zeolite frameworks, ${ }^{[42,97,98]}$ the "averaging effect" is especially evident for the $\mathrm{O}$ positions due to the inherent flexibility of the $\mathrm{Si}-\mathrm{O}-\mathrm{Si}$ angles. Overall, such a comparison underlines quite a good agreement between calculated and refined framework structures. Focusing now on the polymer structure, a closer inspection of Figure 1o reveals that the two models containing both cyclopentyl units and side moieties (Models D, E) best match the experimental results. On the other hand, the simple linear $\mathrm{C}-\mathrm{C}$ chain of Model A exhibits the worst comparison with the residual maxima of the Fourier map, because of its low steric encumbrance. Indeed, all the other model polymers - which are all bulkier than the simple linear chain - better fit to the $H S-M O R$ main channel, as indicated by the closer $\mathrm{C}$ - $\mathrm{O}_{\text {framework }}$ contacts and evidenced in Figure 1ob-e.
Interestingly, Model B features two carbon symmetrized positions - those corresponding to the terminal methyl group of the propyl branching chain- located in the window between the $12 \mathrm{MR}$ and the side pocket. Therefore, these locations that were ascribed to a $\mathrm{H}_{2} \mathrm{O}$ molecule site $\left(\mathrm{W}_{1}\right)$ in the XRPD refinement - might also be due to terminal methyl groups of propyl side moieties. However, with respect to the cyclopentyl-containing chains in Models C, D, $\mathrm{E}$, the polymer in Model $\mathrm{B}$ would require a higher number of (formal) $\mathrm{H}_{2}$ molecules to saturate the double bond (two per diene molecules).

Hence, on the basis of the comparison of the computational models with the XRPD and spectroscopic data, we propose that the most probable structure of the caged 1,5-hexadiene derived polymer might be similar to Model D - i.e. a 1D-polymer featuring both cyclopentane units and side alkyl moities. The formation of polymers containing vinyltetramethylene (VTM) units from 1,5hexadiene, which may undergo subsequent functionalization, has been documented to occur with homogeneus Ziegler-Natta catalysts. ${ }^{[0,99]}$ Keeping into account the long time scale of the full process as deduced by IR measurements (one week), model E featuring vinyl side groups between cyclic units - might be a plausible representation of a possible first product of the 
polymerization, which could probably proceed via both insertioncyclizations and successive 1,2 insertions of 1,5 -hexadiene units.

\section{Conclusion}

In this work we adopted a multidisciplinary approach to study the fate of a flexible guest $\alpha, \omega$-diene molecule $(1,5$-hexadiene) hosted in the channels of a moderately acid zeolite. Such a molecule is known to produce different moieties and even oligomers or polymers in homogeneous media, whose chain length and microstructure is very sensitive to the catalyst structure and to the adopted conditions. Here we showed that, in confining hydrophobic nanochannels at ambient conditions, the guest molecules undergo a slow transformation to a continuous polymeric chain, consisting of cyclic units intercalated by short side chains, that nicely fits to the host channels. Importantly, despite the appearance of olefinic side groups along the main chain in the course of the process, cross linking is prevented by the confining environment of the zeolite channel, which forces a linear growth of the polymer. Hence, our work evidences the relevance of the size-shape geometrical constraints of zeolite channels to drive organization at molecular level. Thanks to the presence of few acid sites evenly distributed along the channel walls, once the molecules are properly organized inside the voidspace architecture, they are prone to react yielding quasi monodimensional polymers, whose structure is shaped by the geometrical features of the zeolite mold. In addition, the IR monitoring has shown that the silanols of $H S-M O R$ are strong enough to protonate an adsorbed electron-donor probe. This kind of reactivity, not often observed for high-silica zeolites, accounts for the formation of observed carbocations and for the polymerisation of 1,5 -hexadiene in very mild conditions of temperature and concentration. The next challenge would be to achieve further control of the microstructure and stereochemistry of the confined polymer. This goal could be accomplished by integrated experimental and theoretical investigations of this intriguing phenomenon aimed at understanding its delicate mechanistic aspects, for example by varying the reaction conditions of the shape-directed polymerization process. Beside opening fascinating questions on the inner machinery of confined polymerization, our results underline that zeolite frameworks are also effective in directing covalent bonds' cleavage-formation events at room conditions, leading to arrays of polymers, each shaped by the zeolite mold. This awareness may further encourage the production of encapsulated arrays of lowdimensionality organic polymeric nanostructures with potential application in a variety of end uses.

\section{Experimental Section}

\section{Materials}

High-silica mordenite (HS-MOR, $\mathrm{SiO}_{2} / \mathrm{Al}_{2} \mathrm{O}_{3}$ ratio 200; $\mathrm{Na}_{2} \mathrm{O}<0.1$ wt.\%) was purchased from the Tosoh Corporation (Japan) in its protonated form (code HSZ-69oHOA). 1,5-hexadiene (abbreviated hexa, $\mathrm{C}_{6} \mathrm{H}_{10}$ ) was purchased from Sigma-Aldrich ( $97 \%$ purity).

\section{High-silica mordenite loading}

The loading of 1,5-hexadiene was performed on a previously outgassed $H S$ $M O R$ at room temperature (r.t.) for $1 \mathrm{~h}$, in order to remove physisorbed water, by contacting the zeolite powder with 50 mbar of 1,5-hexadiene vapor for an increasing amount of time up to one week at r.t. followed by in situ IR spectroscopy. Samples were then outgassed (1 h, r.t.) and exposed to air before thermogravimetric and X-ray Powder Diffraction (XRPD) measurements. The loaded sample are labelled HS-MOR hexa.

\section{Thermogravimetric analysis}

TG analyses of pure HS-MOR and of HS-MOR hexa were carried out using an SDT Q6oo thermal analyzer from TA Instruments by an initial fluxing of the sample under nitrogen for $60 \mathrm{~min}$ at $50^{\circ} \mathrm{C}$ in the sample chamber to remove environmental fluctuations, then by increasing the temperature from 50 up to $800^{\circ} \mathrm{C}$ with a ramp of $10^{\circ} \mathrm{C} / \mathrm{min}$ under synthetic air flow.

\section{IR experiments}

Absorption IR spectra were collected at r.t. with a Perkin-Elmer FT-IR System 2000 spectrophotometer equipped with an MCT detector, working in the range of wavenumbers $7200-580 \mathrm{~cm}^{-1}$ at a resolution of $2 \mathrm{~cm}^{-1}$ (number of scans 64). For IR analysis the powder of HS-MOR was compressed in self-supporting discs, with an optical thickness of about 10 $\mathrm{mg} \mathrm{cm} \mathrm{cm}^{-2}$, placed in a home-made quartz IR cell equipped with $\mathrm{KBr}$ windows and connected to a glass vacuum line (residual pressure: $1 \mathrm{X1O}^{-4}$ mbar), allowing in situ adsorption and desorption experiments to be carried out. The spectrum of 1,5-hexadiene in the vapor phase was collected introducing the vapors of the molecule at $\mathrm{p}=\mathbf{2 5} \mathrm{mbar}$ in a cell for gas measurements, with an optical path of $10 \mathrm{~cm}$.

\section{XRPD experiments}

$\mathrm{X}$-ray powder diffraction experiment was performed at ID15b beamline of ESRF (Grenoble) on the 1,5-hexadiene-loaded samples (HS-MOR hexa). The powder was placed in a $0.3 \mathrm{~mm}$ quartz capillary mounted on a goniometric spinning head. The diffraction data $(\lambda=0.412015 \AA)$ were collected in the Debye-Scherrer geometry on a MAR555 detector with a sample-distance of $547.5 \mathrm{~mm}$. A one-dimensional diffraction pattern was obtained by integrating the two-dimensional images with the program Dioptas $^{[100]}$. A preliminary data collection of HS-MOR hexa was performed at ID22 beamline at ESRF.

Rietveld profile fitting was performed in the $\mathrm{Cmcm}$ space group using the GSAS package ${ }^{[101]}$ with the EXPGUI ${ }^{[102]}$ interface, starting from the framework atomic coordinates reported in. ${ }^{[101]}$ The extra-framework sites (water and organic moieties) were localized from the difference Fourier map. The background curve was fitted using a Chebyshev polynomial with 28 coefficients. The pseudo-Voigt profile function proposed by Thompson and coauthors ${ }^{[103]}$ was used with a peak intensity cut-off set to $0.1 \%$ of the strongest peak. Soft-restraints were applied to the T-O distances (1.6o $\AA$ ) and C-C distances (1.5 $\AA$ ), their weight was set at 10oo. The isotropic displacement parameters were constrained in the following way: a value for all the tetrahedral cations ( $\mathrm{Si}$ ), a second value for all the framework oxygen atoms, a third value for the carbon atoms and a fourth one for $\mathrm{H}_{2} \mathrm{O}$ molecules.

\section{Theoretical Calculations}

Our computational models for HS-MOR hexa contain two MOR crystallographic unit cells along the $c$ direction. The total volume of the simulation cell was $\mathrm{a} \times \mathrm{b} \times 2 \mathrm{c}$, where the $a, b$, and $c$ parameters were the ones experimentally determined for $H S-M O R$ hexa. Due to the very low density of Brønsted acid sites experimentally detected with respect to the 
simulation cell size (less than one acid site per simulation cell), the host was modeled as an all-silica MOR framework with stoichiometry $\left[\mathrm{Si}_{96} \mathrm{O}_{192}\right]$ per simulation cell (p.s.c.). This framework model was then filled with putative models of continuous 1-D polymers that might be formed upon polymerization of 1,5 -hexadiene moieties. In particular, we considered five models of 1,5-hexadiene based polymers (depicted in figure 2), labelled as A, B, C, D, E and with stoichiometry p.s.c. equal to $\mathrm{C}_{12} \mathrm{H}_{24}, \mathrm{C}_{18} \mathrm{H}_{36}, \mathrm{C}_{18} \mathrm{H}_{30}$, $\mathrm{C}_{18} \mathrm{H}_{32}$, and $\mathrm{C}_{18} \mathrm{H}_{30}$, respectively. Only one channel of the framework was filled with polymer models. All the above-mentioned model systems were simulated using a Density-Functional-Theory (DFT) computational approach. As DFT approximation, we used PBE with dispersion corrections. ${ }^{[104]}$ Although the DFT machinery surely has limitations due to self-interactions ${ }^{[105,106]}$ for most purposes such scheme delivers a satisfactory accuracy- at a viable cost, as evidenced by benchmark calculations on various zeolitic frameworks. ${ }^{[107-112]}$ The selection of PBE-D2 for the present case was prompted by its reliability in reproducing the average framework structure of $\mathrm{LTL}^{\left[{ }^{[13]}\right]}$ high-silica ferrierite, ${ }^{[42,98]}$ and chabazite ${ }^{[97]}$ obtained from in situ diffraction experiments. Such protocol delivers an adequate description of physico-chemical properties of molecules at material interfaces. ${ }^{[14-119]}$ The computational cell was large enough to perform gamma-point only calculations. ${ }^{[20]}$ The guess for the various models were built using the optimized geometry of this framework (simulation cell stoichiometry $=\left[\mathrm{Si}_{96} \mathrm{O}_{192}\right]$ ) as a starting point. Prior to geometry optimization, all models were annealed by means of ab initio molecular dynamics (AIMD) ${ }^{[120,121]}$ trajectories. Our selected time step was $0.121 \mathrm{fs}$, the inertia parameter for the electronic coefficients was 500 a.u. The plane-wave-basis set size was determined by the wavefunction cutoff (25 Ry) and density cutoff (200 Ry). The selected theoretical methodology treats the interactions of electrons with the ionic cores by means of pseudopotentials: of the ultrasoft type $\mathrm{e}^{[122]}$ for $\mathrm{O}, \mathrm{C}, \mathrm{H}$, and norm conserving with non-linear core corrections ${ }^{[23]}$ for Si. Importantly, no symmetry constraints were imposed to the atomic positions during the calculations, only the simulation cell parameters (with periodic boundary conditions) were kept fixed at the experimental values. Our convergence criterion for geometry optimizations required a maximum force on the ions below $1 \times 10^{-4}$ Hartree/Bohr. ${ }^{[120]}$ Minimum energy structures were obtained by optimization of the above mentioned models using different initial guess configurations. The different number of atoms composing the polymers prevents a direct comparison of their formation energies. For each of these five systems, the lowest energy geometry was selected to evaluate the binding energy of the polymer chain inside HS-MOR. Binding energies were evaluated with the following equation:

\section{$\Delta E(H S-M O R$ hexa $)=E(H S-M O R$ hexa $)-E(H S-M O R)-E($ hexa $)$}

Where $\Delta \mathrm{E}$ is the binding energy of the composite, while $E$ (HS-MOR hexa), $\mathrm{E}(H S-M O R), E($ hexa) represent the total energy of the composite, of the empty $H S-M O R$, and of the hexa based polymeric chain, respectively, all calculated in the same simulation cell. Negative values of the binding energy denote a favorable interaction of the polymer with HS-MOR. Binding energies reported in the text are expressed in kcal per mol of simulation cell. The CPMD code ${ }^{[124]}$ was used for all calculations. The computed structures were visualized with the VMD and Avogadro codes. $^{[25]}$

\section{Acknowledgements}

This work was carried out in the framework of the PRIN project ZAPPING (PRIN2015 Prot.2015HK93L7) funded by the Italian MIUR. FAR2018 Uninsubria is acknowledged for funding. M. Fabbiani is gratefully indebted to C. Nannuzzi for the support in the in situ experiments and data elaborations. Authors thank the staff of ID15b and ID22, ESRF, for the help in X-ray diffraction data collection.
Keywords: zeolites $\cdot$ polymerization $\cdot$ nanostructures $\bullet$ density functional calculations $\bullet$ infrared spectroscopy $\bullet$ X-Ray Diffraction

[1] U. Díaz, A. Corma, Chem. - A Eur. J. 2018, 24, 3944-3958

[2] G. Calzaferri, S. Huber, H. Maas, C. Minkowski, Angew. Chemie - Int. Ed. 2003, 42, 3732-3758.

[3] H. Garcia, V. I. Parvulescu, Catal. Sci. Technol. 2o18, 8, 4834-4857.

[4] E. M. Gallego, C. Li, C. Paris, N. Martín, J. Martínez-Triguero, M.

Boronat, M. Moliner, A. Corma, Chem. - A Eur. J. 2018, 24, 14631-14635.

F. Cucinotta, A. Guenet, C. Bizzarri, W. Mroz, C. Botta, B. MilianMedina, J. Gierschner, L. De Cola, Chempluschem 2o14, 79, 45-57.

6] A. Corma, H. Garcia, Eur. J. Inorg. Chem. 2004, 2004, 1143-1164.

[7] D. Balestri, P. P. Mazzeo, C. Carraro, N. Demitri, P. Pelagatti, A. Bacchi, Angew. Chemie Int. Ed. 2019, 58, 17342-17350.

[8] G. Campillo-Alvarado, M. M. D'mello, M. A. Sinnwell, H. Höpfl, H. Morales-Rojas, L. R. MacGillivray, Front. Chem. 2019, 7, 695.

[9] G. L. Hill, E. Bailey, M. C. Stennett, N. C. Hyatt, E. M. Maddrell, P. F. McMillan, J. A. Hriljac, J. Am. Chem. Soc. 2011, 133, 13883-13885.

[10] P. Lu, L. Gómez-Hortigüela, M. A. Camblor, Chem. - A Eur. J. 2019, 25 1561-1572.

[11] G. Tabacchi, ChemPhysChem 2018, 19, 1249-1297.

[12] J. Čejka, A. Corma, S. Zones, Zeolites and Catalysis: Synthesis, Reactions and Applications, Volume 2, WILEY-VCH Verlag GmbH \& Co. KGaA, Weinheim, Germany, 2010.

[13] E. Fois, G. Tabacchi, S. Quartieri, G. Vezzalini, J. Chem. Phys. 1999, 111, 355-359.

[14] S. Quartieri, A. Sani, G. Vezzalini, E. Galli, E. Fois, A. Gamba, et al, Microporous Mesoporous Mater. 1999, 30, 77-87.

[15] E. Fois, A. Gamba, C. Medici, G. Tabacchi, S. Quartieri, E. Mazzucato, R. Arletti, G. Vezzalini, V. Dmitriev, Microporous Mesoporous Mater. 2008, 115, 267-280.

[16] A. R. Morgado Prates, F. Meunier, M. Dodin, R. Martinez Franco, D. Farrusseng, A. Tuel, Chem. - A Eur. J. 2019, 25, 2972-2977.

[17] R. Bueno-Perez, S. R. G. Balestra, M. A. Camblor, J. G. Min, S. B. Hong, P. J. Merkling, S. Calero, Chem. - A Eur. J. 2018, 24, 4121-4132.

[18] L. R. Aramburo, L. Karwacki, P. Cubillas, S. Asahina, D. A. M. De Winter, M. R. Drury, I. L. C. Buurmans, E. Stavitski, D. Mores, M. Daturi, et al., Chem. - A Eur. J. 2011, 17, 13773-13781.

[19] A. M. Pintus, A. Gabrieli, F. G. Pazzona, G. Pireddu, P. Demontis, Phys. Chem. Chem. Phys. 2019, 21, 7879-7884.

[20] H. I. Hamoud, M. Lafjah, F. Douma, O. I. Lebedev, F. Djafri, V. Valchev, M. Daturi, M. El-Roz, Sol. Energy 2019, 189, 244-253.

[21] D. Comboni, F. Pagliaro, P. Lotti, G. D. Gatta, M. Merlini, S. Milani, M. Migliori, G. Giordano, E. Catizzone, I. E. Collings, et al., Catal. Today 2020, 345, 88-96.

[22] J. Dědeček, Z. Sobalík, B. Wichterlová, Catal. Rev. - Sci. Eng. 2012, 54 , 135-223.

[23] F. C. Hendriks, J. E. Schmidt, J. A. Rombouts, K. Lammertsma, P. C. A. Bruijnincx, B. M. Weckhuysen, Chem. - A Eur. J. 2017, 23, 6305-6314. M. Zaarour, H. El Siblani, N. Arnault, P. Boullay, S. Mintova, Materials 2019, 12, 2830.

Materials 2019, 12, 2830.
[25] P. Cao, O. Khorev, A. Devaux, L. Sägesser, A. Kunzmann, A. Ecker, R. Häner, D. Brühwiler, G. Calzaferri, P. Belser, Chem. - A Eur. J. 2016, 22, 4046-406o.

[26] I. Lõpez-Duarte, Le-Quyenha Dieu, I. Dolamic, M. V. Martínez-Díaz, T. Torres, G. Calzaferri, D. Brühwiler, Chem. - A Eur. J. 2011, 17, 18551862.

[27] X. Zhou, T. A. Wesolowski, G. Tabacchi, E. Fois, G. Calzaferri, A. Devaux, Phys. Chem. Chem. Phys. 2013, 15, 159-167.

[28] H. Manzano, L. Gartzia-Rivero, J. Bañuelos, I. López-Arbeloa, J. Phys. Chem. C 2013, 117, 13331-13336.

[29] G. Tabacchi, E. Fois, G. Calzaferri, Angew. Chemie Int. Ed. 2015, 54, 11112-11116.

[30] G. Calzaferri, H. Li, D. Brühwiler, Chem. - A Eur. J. 2oo8, 14, 7442..

[31] L. Gigli, R. Arletti, G. Tabacchi, M. Fabbiani, J. G. Vitillo, G. Martra, A. Devaux, I. Miletto, S. Quartieri, G. Calzaferri, et al., J. Phys. Chem. C 2018, 122, 3401-3418.

[32] P. Woodtli, S. Giger, P. Müller, L. Sägesser, N. Zucchetto, M. J. Reber, A. Ecker, D. Brühwiler, Dye. Pigment. 2018, 149, 456-461.

[33] R. Sola-Llano, V. Martínez-Martínez, Y. Fujita, L. Gómez-Hortigüela, A. Alfayate, H. Uji-i, E. Fron, J. Pérez-Pariente, I. López-Arbeloa, Chem. - A Eur. J. 2016, 22, 15700-15711.

[34] A. Bertucci, H. Lülf, D. Septiadi, A. Manicardi, R. Corradini, L. De Cola, Adv. Healthc. Mater. 2014, 3, 1812-1817.

[35] L. Giussani, G. Tabacchi, S. Coluccia, E. Fois, Int. J. Mol. Sci. 2019, 20, 2965.

[36] F. Cucinotta, F. Carniato, A. Devaux, L. De Cola, L. Marchese, Chem. A Eur. J. 2012, 18, 15310-15315.

[37] G. Tabacchi, E. Gianotti, E. Fois, G. Martra, L. Marchese, S. Coluccia, A. Gamba, J. Phys. Chem. C 20o7, 111, 4946-4955. 
L. Grösch, Y. J. Lee, F. Hoffmann, M. Fröba, Chem. - A Eur. J. 2015, 21, 331-346.

[39] E. Fois, A. Gamba, G. Tabacchi, S. Coluccia, G. Martra, J. Phys. Chem. B 2003, 107, 10767-10772.

[4o] A. J. Bagnall, M. Santana Vega, J. Martinelli, K. Djanashvili, F. Cucinotta, Chem. - A Eur. J. 2018, 24, 11992-11999.

[41] A. J. Sindt, M. D. Smith, S. Berens, S. Vasenkov, C. R. Bowers, L. S. Shimizu, Chem. Commun. 2019, 55, 5619-5622.

[42] R. Arletti, E. Fois, L. Gigli, G. Vezzalini, S. Quartieri, G. Tabacchi, Angew. Chemie - Int. Ed. 2017, 56, 2105-2109.

[43] G. D. Gatta, P. Lotti, G. Tabacchi, Phys. Chem. Miner. 2018, 45, 115-138.

[44] L. Gigli, R. Arletti, E. Fois, G. Tabacchi, S. Quartieri, V. Dmitriev, G. Vezzalini, Crystals 2018, 8, 79 .

[45] D. J. Cardin, Adv. Mater. 2002, 14, 553-563.

[46] C. Pereira, G. T. Kokotailo, R. J. Gorte, J. Phys. Chem. 1991, 95, 705709.

[47] F. A. Zhang, D. K. Lee, T. J. Pinnavaia, Polym. Chem. 2010, 1, 107-113.

[48] A. Comotti, S. Bracco, M. Beretta, J. Perego, M. Gemmi, P. Sozzani, Chem. - A Eur. J. 2015, 21, 18209-18217.

[49] S. Mochizuki, T. Kitao, T. Uemura, Chem. Commun. 2018, 54, 11843 11856.

[5o] K. Tajima, T. Aida, Chem. Commun. 200o, o, 2399-2412.

[51] M. Chołuj, W. Bartkowiak, Int. J. Quantum Chem. 2019, e25997.

[52] M. Santoro, F. A. Gorelli, R. Bini, J. Haines, A. van der Lee, Nat. Commun. 2013, 4, 1557.

[53] D. Scelta, M. Ceppatelli, M. Santoro, R. Bini, F. A. Gorelli, A. Perucchi, M. Mezouar, A. Van Der Lee, J. Haines, Chem. Mater. 2014, 26, 22492255 .

M. Santoro, K. Dziubek, D. Scelta, M. Ceppatelli, F. A. Gorelli, R. Bini, J. M. Thibaud, F. Di Renzo, O. Cambon, J. Rouquette, et al., Chem. Mater. 2015, 27, 6486-6489.

[55] G. Confalonieri, M. Fabbiani, R. Arletti, S. Quartieri, F. Di Renzo, J. Haines, et al., Microporous Mesoporous Mater. 2020, 300, 110163.

[56] T. Bein, P. Enzel, Angew. Chem. Int. Ed. Eng. 1989, 28, 1692-1694.

[57] G. F. McCann, G. J. Millar, G. A. Bowmaker, R. P. Cooney, J. Chem. Soc. Faraday Trans. 1995, 91, 4321-4328.

[58] M. Sierka, U. Eichler, J. Datka, J. Sauer, J. Phys. Chem. B 1998, 102, 10468-10468.

[59] E. Fois, A. Gamba, G. Tabacchi, J. Phys. Chem. B 1998, 102, 3974-3979.

[6o] R. Grau-Crespo, A. G. Peralta, A. R. Ruiz-Salvador, A. Gómez, R. López-Cordero, Phys. Chem. Chem. Phys. 2ooo, 2, 5716-5722.

[61] X. Rozanska, R. A. Van Santen, F. Hutschka, J. Hafner, J. Catal. 2oo2, 205, 388-397.

[62] C. O. Arean, M. R. Delgado, P. Nachtigall, H. V. Thang, M. Rubeš, R. Bulánek, P. Chlubná-Eliášová, Phys. Chem. Chem. Phys. 2014, 16, 10129-10141.

[63] V. Pashkova, S. Sklenak, P. Klein, M. Urbanova, J. Dědeček, Chem. - A Eur. J. 2016, 22, 3937-3941.

[64] G. Li, E. A. Pidko, ChemCatChem 2019, 11, 134-156.

[65] M. Fischer, Chem. - A Eur. J. 2o19, 25, 13579-13590.

[66] M. Jaymand, RSC Adv. 2014, 4, 33935-33954.

[67] P. Lotti, G. D. Gatta, M. Merlini, H.-P. Liermann, Zeitschrift für Krist. - Cryst. Mater. 2015, 230, 201-211.

[68] J. L. Mackey, Z. Yang, K. N. Houk, Chem. Phys. Lett. 2017, 683, 253257.

[69] D. Walther, T. Döhler, K. Heubach, O. Klobes, B. Schweder, H. Görls, Zeitschrift fur Anorg. und Allg. Chemie 1999, 625, 923-932.

[7o] P. D. Hustad, G. W. Coates, J. Am. Chem. Soc. 2002, 124, 11578-11579.

[71] H. M. Jeong, J. H. Song, K. W. Chi, I. Kim, K. T. Kim, Polym. Int. 20o2, 51, 275-280.

[72] G. J. Domski, J. M. Rose, G. W. Coates, A. D. Bolig, M. Brookhart, Prog. Polym. Sci. 2007, 32, 30-92.

[73] X. Shi, Y. Wang, J. Liu, D. Cui, Y. Men, Y. Li, Macromolecules 2o11, 44, 1062-1065.

[74] L. Cavallo, G. Guerra, P. Corradini, L. Resconi, R. M. Waymouth, Macromolecules 1993, 26, 260-267.

[75] O. R. De Ballesteros, V. Venditto, F. Auriemma, G. Guerra, L. Resconi, R. Waymouth, A. L. Mogstad, Macromolecules 1995, 28, $2383-2388$.

[76] W. M. Meier, Zeitschrift fur Krist. - New Cryst. Struct. 1961, 115, 439450 .

[77] C. Baerlocher, L. B. McCusker, D. H. Olson, Atlas of Zeolite Framework Types, Elsevier, 2007

[78] R. Arletti, A. Martucci, A. Alberti, L. Pasti, M. Nassi, R. Bagatin, J. Solid State Chem. 2012, 194, 135-142.

[79] A. Martucci, L. Pasti, M. Nassi, A. Alberti, R. Arletti, R. Bagatin, R. Vignola, R. Sticca, Microporous Mesoporous Mater. 2012, 151, 358-367.

[8o] S. Blasioli, A. Martucci, G. Paul, L. Gigli, M. Cossi, C. T. Johnston, L. Marchese, I. Braschi, J. Colloid Interface Sci. 2014, 419, 148-159.

[81] R. Arletti, L. Leardini, G. Vezzalini, S. Quartieri, L. Gigli, M. Santoro, J. Haines, J. Rouquette, L. Konczewicz, Phys. Chem. Chem. Phys. 2015, $17,24262-24274$.
[82] R. Fantlini, R. Arletti, S. Quartieri, M. Fabbiani, S. Morandi, G. Martra, F. Di Renzo, G. Vezzalini, Microporous Mesoporous Mater. 2020, 294, 109892.

[83] Y. Hu, G. Martra, J. Zhang, S. Higashimoto, S. Coluccia, M. Anpo, J. Phys. Chem. B 2006, 110, 1680-1685.

[84] V. Bolis, C. Busco, S. Bordiga, P. Ugliengo, C. Lamberti, A. Zecchina, in Appl. Surf. Sci., Elsevier, 2002, pp. 56-70.

[85] H. Hattori, P. Arudra, A. Abdalla, A. M. Aitani, S. S. Al-Khattaf, Catal. Letters 2020, 150, 771-780.

[86] C. Pazè, B. Sazak, A. Zecchina, J. Dwyer, J. Phys. Chem. B 1999, 103, 9978-9986.

[87] N. B. Colthup, L. H. Daly, S. E. Wiberly, Introduction to Infrared and Raman Spectroscopy, Academic Press, New York, 1975.

[88] G. Herzberg, Molecular Spectra and Molecular Structure. II. Infrared and Raman Spectra of Polyatomic Molecules, Van Nostrand Company, Princeton, New Jersey, US, 1962.

[89] L. Gigli, R. Arletti, G. Tabacchi, E. Fois, J. G. Vitillo, G. Martra, G. Agostini, S. Quartieri, G. Vezzalini, J. Phys. Chem. C 2014, 118, 1573215743 .

[9o] G. Tabacchi, G. Calzaferri, E. Fois, Chem. Commun. 2016, 52, $11195^{-}$ 11198.

[91] E. Fois, G. Tabacchi, G. Calzaferri, J. Phys. Chem. C 2012, 116, 1678416799.

[92] W. Insuwan, K. Rangsriwatananon, J. Meeprasert, S. Namuangruk, Y. Surakhot, N. Kungwan, S. Jungsuttiwong, Microporous Mesoporous Mater. 2017, 241, 372-382.

[93] M. Fischer, J. Phys. Chem. C 2020, 124, 5690-5701.

[94] V. Martínez-Martínez, R. García, L. Gómez-Hortigüela, J. PérezPariente, I. López-Arbeloa, Chem. - A Eur. J. 2013, 19, 9859-9865.

[95] G. W. Coates, R. M. Waymouth, J. Am. Chem. Soc. 1991, 113, 6270-6271.

[96] K. Nomura, Y. Hatanaka, H. Okumura, M. Fujiki, K. Hasegawa, Macromolecules 2004, 37, 1693-1695.

[97] G. Confalonieri, S. Quartieri, G. Vezzalini, G. Tabacchi, E. Fois, T. J. Daou, R. Arletti, Microp. Mesoporous Mater. 2019, 284, 161-169.

[98] F. Trudu, G. Tabacchi, E. Fois, Am. Mineral. 2019, 104, 1546-1555.

[99] R. T. Mathers, G. W. Coates, Chem. Commun. 2004, 10, 422-423.

[10o] C. Prescher, V. B. Prakapenka, High Press. Res. 2015, 35, 223.

[101] A. C. Larson, R. B. Von Dreele, 1994, LAUR 86-748.

[102] B. H. Toby, J. Appl. Crystallogr. 2001, 34, 210-213.

[103] P. Thompson, D. E. Cox, J. B. Hastings, J. Appl. Crystallogr. 1987, 20, 79-83.

[104] S. Grimme, J. Comput. Chem. 2oo6, 27, 1787-1799.

[105] E. S. Fois, J. I. Penman, P. A. Madden, J. Chem. Phys. 1993, 98, 63526360.

[106] J. Klimeš, D. P. Tew, J. Chem. Phys. 2019, 151, 234108.

[107] M. Fischer, W. J. Kim, M. Badawi, S. Lebègue, J. Chem. Phys. 2019, 150, 094102.

[108] M. Fischer, F. O. Evers, F. Formalik, A. Olejniczak, Theor. Chem. Acc. 2016, 135, 257.

[109] M. Fischer, M. R. Delgado, C. O. Areán, C. O. Duran, Theor. Chem. Acc. 2015, 134, 91.

[110] H. Hay, G. Ferlat, M. Casula, A. P. Seitsonen, F. Mauri, Phys. Rev. B 2015, $92,144111$.

[111] F. Trudu, G. Tabacchi, A. Gamba, E. Fois, J. Phys. Chem. A 2007, 111, 11626-37.

[112] M. Abatal, A. R. Ruiz-Salvador, N. C. Hernández, Microporous Mesoporous Mater. 2020, 109885.

[113] E. Fois, G. Tabacchi, Zeitschrift fur Krist. 2019, 234, 495-511.

[114] G. Bandoli et al., Phys. Chem. Chem. Phys. 2009, 11, 5998.

[115] E. Fois, G. Tabacchi, D. Barreca, A. Gasparotto, E. Tondello, Angew. Chemie - Int. Ed. 2010, 49, 1944-1948.

[116] D. Barreca, E. Fois, A. Gasparotto, R. Seraglia, E. Tondello, G. Tabacchi, Chem. - A Eur. J. 2o11, 17, 10864-10870.

[117] C. Maccato, L. Bigiani, G. Carraro, A. Gasparotto, R. Seraglia, J. Kim, A. Devi, et al., Chem. - A Eur. J. 2017, 23, 17954-17963.

[118] G. Tabacchi, M. Fabbiani, L. Mino, G. Martra, E. Fois, Angew. Chemie Int. Ed. 2019, 58, 12431-12434.

[119] C. Deiana, E. Fois, G. Martra, S. Narbey, F. Pellegrino, G. Tabacchi, ChemPhysChem 2016, 17, 1956-196o.

[120] D. Marx, J. Hutter, Ab Initio Molecular Dynamics, Cambridge University Press, Cambridge, 2009

[121] R. Car, M. Parrinello, Phys. Rev. Lett. 1985, 55, 2471-2474.

[122] D. Vanderbilt, Phys. Rev. B 1990, 41, 7892-7895.

[123] N. Troullier, J. L. Martins, Phys. Rev. B 1991, 43, 1993-2006.

[124] IBM Corp. 1990-2017, MPI für Festkörperforschung Stuttgart 19972001, 2017.

[125] a) W. Humphrey, A. Dalke, K. Schulten, J. Mol. Graph. 1996, 14, 33-38; b) M. D Hanwell, D. E. Curtis, D. C. Lonie, T. Vandermeersch, E. Zurek, G. R. Hutchison, J. Cheminform. 2012, 4,17. 


\section{TOC graphics}

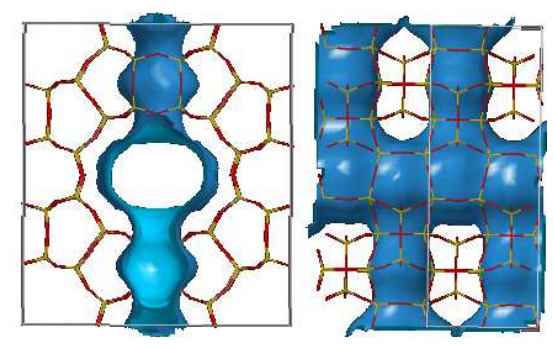

The channel system of zeolite mordenite, highlighting the void-space architecture constituted by the 12membered ring channel and the side pockets.

(Image created using the Database of Zeolite Structures, Structure Commission of the International Zeolite Association

https://europe.iza-structure.org/IZA-SC/framework.php?STC=MOR ) 